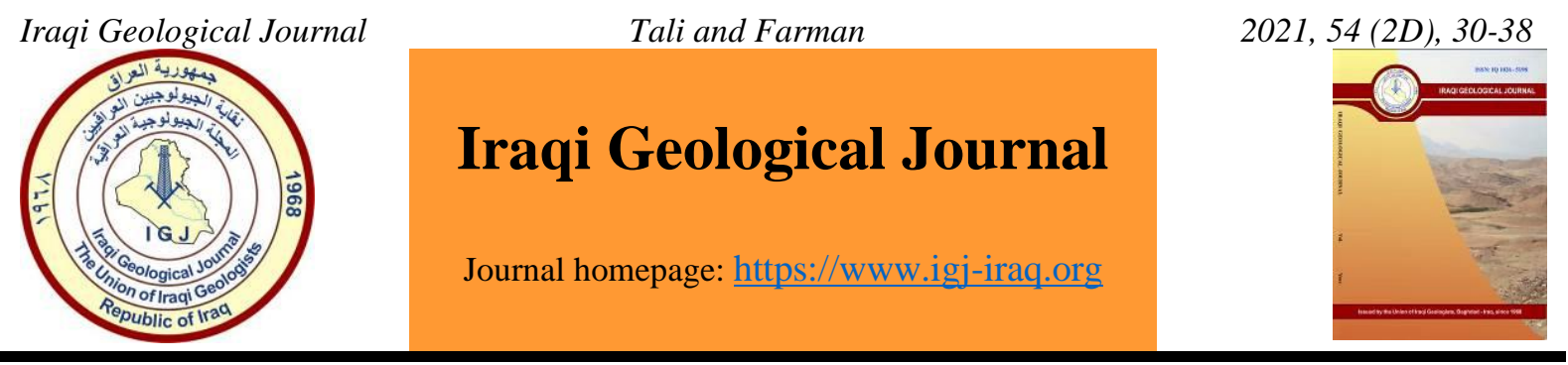

\title{
Use Conventional and Statistical Methods for Porosity Estimating in Carbonate Reservoir in Southern Iraq, Case Study
}

\author{
Ali Hussein Tali ${ }^{*}$ and Ghanim M. Farman ${ }^{1}$ \\ 1 Department of Petroleum Engineering, College of Engineering, University of Baghdad, Baghdad, Iraq \\ * Correspondence: a.tali1908m@coeng.uobaghdad.edu.iq
}

Received:10 June 2021; Accepted: 26 July 2021; Published: 31 October 2021

\begin{abstract}
Porosity is important because it reflects the presence of oil reserves. Hence, the number of underground reserves and a direct influence on the essential petrophysical parameters, such as permeability and saturation, are related to connected pores. Also, the selection of perforation interval and recommended drilling additional infill wells. For the estimation two distinct methods are used to obtain the results: the first method is based on conventional equations that utilize porosity logs. In contrast, the second approach relies on statistical methods based on making matrices dependent on rock and fluid composition and solving the equations (matrices) instantaneously. In which records have entered as equations, and the matrix is solved in one step, the porosity, saturation, and volume of minerals embedded inside the rock formations were obtained. The results indicated that the porosity was determined using statistical and conventional approaches matched to the core porosity. In the end, statistical techniques afford a different path for calculation and provide outcomes that can be used in all situations, particularly when the rock has many types of components. Furthermore, it is not based on conventional equations and overcomes the problems coming from the unreliability of porosity logs in formations containing mixed minerals.
\end{abstract}

Keywords: Statistical methods; Conventional approaches; Porosity

\section{Introduction}

The ratio of a rock's pore volume to its bulk volume is known as porosity. The fluids enclosed inside the pore spaces of the reservoir rocks might be gas, oil, or water (Awadh et al., 2018 and AlBaldawi, 2021). A high porosity value implies a high potential for loading these fluids in the reservoir rocks, while a low porosity value indicates the inverse (Ellis and Singer, 2007). Total porosity minus the fraction of pore space filled by shale equals effective porosity. It reflects the proportion of interconnected pore volume to the overall volume of reservoir rock containing hydrocarbon and bound water (Awadh et al., 2019). Absolute porosity equals effective porosity in very clean sands. Secondary porosity occurs after the rock is deposited, in contrast to primary porosity, which is defined as the rock's porosity during deposition (Boschetti et al., 2020). It appears due to chemical leaching in carbonate rocks or as fracture spaces in fractured reservoirs (Nasser et al., 2017).

Absolute porosity, effective porosity, and secondary porosity are the three types of porosity calculated by neutron logs, density logs, and sonic logs in a deterministic model. However, when the

DOI: $\underline{10.46717 / \text { igj.54.2D.3Ms-2021-10-22 }}$ 
mineralogy is unknown, the records are of low quality and the formation contains a mixture of heavy minerals limestone, anhydrite, marl, dolomite, siderite, quartz, and clays, a specific solution (primary method) based on deterministic equations is useless, so a multimineral/statistical model is favored over a deterministic model (Cannon, 2015). The effective porosity model is built depending on the porosity $\operatorname{logs}$ (density, neutron, and sonic logs). Effective porosity is used in petrophysical modelling because it provides accurate volumetric results (Mahdi, 2020). The distribution of porosity types in the formation, specifically primary and secondary porosity, can be determined using a comprehensive investigation. Based on the log interpretation of petrophysical data vs depth, various types were identified in the carbonate interval. In general, a facies distribution in the rock correlates to a porosity unit interval. The top of the structure, which depicts high-energy conditions, had the highest amounts of porosity. While in the deep flanks, the situation has decreased (Idan et al., 2020)

The statistical method is built based on a creation of matrixes (log reading $=$ volume fraction $*$ pure reading), where each log represents a linear equation, such as density log and gamma-ray log when the reading is directly related to the matrix density and fluid in, or non-linear if other parameters influence like compaction (Darling, 2005). The primary purpose of this study is to calculate porosity in many different ways. The results were compared to the core sample results and chose the best saturation and reserve calculations (Schlumberger,1989).

\section{Materials and Methods}

\subsection{Conventional method}

Different approaches are used to calculate the total porosity from the available log data, and they are the most commonly used (Schmidt et al., 1971):

From sonic $\log \left(\emptyset_{\text {sonic }}\right)$

$$
\emptyset_{\text {sonic }}=\frac{\Delta t_{\text {log }}-\Delta t_{\text {matrix }}}{\Delta t_{f}-\Delta t_{\text {matrix }}}
$$

$\Delta \mathrm{t}_{\text {matrix }}$ : Matrix transit time $(\mu \mathrm{sec} / \mathrm{ft}), \Delta \mathrm{t}_{\text {log }}$ : sonic transit time $(\mu \mathrm{sec} / \mathrm{ft}), \Delta \mathrm{t}_{\mathrm{f}}$ : fluid acoustic transit time $(\mu \mathrm{sec} / \mathrm{ft})$

From density $\log \left(\emptyset_{\text {density }}\right)$

$$
\emptyset_{\text {density }}=\frac{\rho_{\text {matrix }}-\rho_{\text {log }}}{\rho_{\text {marix }}-\rho_{\text {fluid }}}
$$

$\rho_{\text {matrix }}$ : matrix density (g/cc), $\rho_{\log }$ :formation density $\log (\mathrm{g} / \mathrm{cc}), \rho_{\text {fluid }}$ :fluid density $(\mathrm{g} / \mathrm{cc})$

From density and neutron $\left(\emptyset_{N D}\right)$

$$
\emptyset_{\mathrm{ND}}=\frac{\emptyset_{\text {Neutron }}+\emptyset_{\text {Density }}}{2}
$$

$\emptyset_{\text {Neutron}}:$ neutron porosity (v/v)

Effective porosity $\left(\emptyset_{\text {effective }}\right)$

$$
\emptyset_{\text {effective }}=\phi_{\text {total }} *(1-\text { Vsh })
$$

$\emptyset_{\text {total }}:$ Total porosity

Vsh: shale volume

Secondary porosity (SPI)

$$
\text { SPI }=\phi_{\text {total }}-\phi_{- \text {sonic }}
$$

\subsubsection{Calculation steps}

- Lithology identification: Calculating accurate porosity becomes more challenging when the matrix lithology is indistinct or when the matrix contains two or more minerals of unidentified proportions. However, the neutron and density logs are sensitive to absolute porosity. Sonic logs usually respond 
only to primary porosity that is similarly distributed. If these complicating situations exist, determining porosity needs more details than a single porosity log provides. Fortunately, density, neutron, and sonic logs all respond differently to matrix minerals, gas or light oils, and pore construction geometry. Neutron-Density plot for lithology identification, M-N Mineral Plot for mineral identify, and MID plot for matrix Identification (Gibrata et al., 2019). The result shows that the rock is limestone with little clay mineral, as shown in Figs.1, 2 and 3.

- Matrix endpoint identification: The $\Delta \mathrm{t}$ matrix was determined by a drawing cross plot between the sonic $\log$ and the neutron $\log$, from neutron porosity equal zero, intersection the best straight line passing through the cloud points and reading sonic $(\Delta \mathrm{t}$ matrix $)$ on the y-axis while $\rho$ matrix was determined by a cross plot between the density log and neutron log in the same Procedure (Figs. 4 and 5).

- Apply the above equations (eq. 1 to eq. 5) for porosity calculation; Fig. 6 summarizes the outcome.

- Final porosity compared the porosity results with core porosity. It discovered that an affinity existed with the density $\log$ (Fig. 7). Therefore, the density $\log$ is considered accurate for porosity measurements. log porosity was corrected by establishing a relationship between the core porosity and the log porosity from existing points and extending it to uncored depth (Fig. 8).

\subsection{Statistical Method}

The statistical method is dependent on three factors: first, measurement (response), which reflects the reading of the collected logs, where each log represents an equation. Secondly, parameters representing the end point's final values, and thirdly, constraints where the boundary conditions such as $\mathrm{SW}=1$ in shale and $\mathrm{SW}+\mathrm{SHc}=1$. Fig .9 shows the diagram of the statistical component, where 1 describes the tool vector in this diagram all instrument details and curves. The volume vector (v) signifies the volume of the form elements. The parameter(c) is the response matrix, which contains the parameter values for what each method would read if each formation part were $100 \%$ complete. The statistical model will evaluate the third corner of the triangle given the data indicated by any two of the triangle's corners. for one component while for multi-component, the equation for each log takes the form

$$
b=\sum_{i}^{n} C_{i} V_{i}
$$

Where n: number of logs, Vi: proportion of the ith component, Ci: log response of the ith pure component, and $b=\log$ response of the formation recorded. In every simultaneous solution of a series, there must always be equations equals to unknowns. The system is defined or deterministic when the number of independent equations in the system matches the number of unknowns. In a determined model, there is only one set of values for the unknowns that will satisfy the equations. The system is underdetermined if there are fewer equations than unknowns. It thus cannot be solved until the problem is restructured by adding individual equations or reducing the number of unknowns. The system is considered to be overdetermined when there are more individual equations than unknowns, and some techniques must be utilized to resolve any disparities between the equations (Cannon, 2015).

In the forward case, $\mathrm{V}$ is computed using $\mathrm{C}$ and $\mathrm{l}$. As previously noted, the forward issue is sometimes seen as the primary responsibility of the statistical program. The inverse issue, often called $\log$ reconstruction, is solved using $\mathrm{C}$ and V. For each forward issue, or Solve process, a $\log$ reconstruction problem is calculated. The rebuilt logs are compared to the input data to assess the quality of the inverse problem's volumetric findings. Finally, the calibration issue is the process of calibrating c using $v$ and $l$ (Ellis and Singer, 2007). 


\subsubsection{Calculation steps}

The following is a simple description of how programs that use this methodology work.

- The various minerals and fluids included in the model are determined in significant quantities.

- The response of each of these minerals and fluids for various parameters as measured by logging tools is specified; choose logs that are sensitive to at least one of the selected formation elements.

- Constraints are commonly used to impose geological or petrophysical data. It represents the minimum, and maximum absolute limits on formation component volumes identify.

- Uncertainties and weight multipliers are calculated based on hole condition, depth of investigation, and measurement error (Fig. 10).

\section{Results}

The results of this study are:

- The density of the matrix is $2.71 \mathrm{~g} / \mathrm{cc}$. This is consistent with the lithology, which has been limestone rock. Clay volume was identical in both mathematical and statistical methods.

- It has a high correlation with the porosity result between the statistical method and the deterministic method (conventional method) with core porosity.

- The porosity of the rock intermediate about 7-11 pu.

- The analysis of the acoustic log reveals the existence of an obvious and substantial secondary porosity.

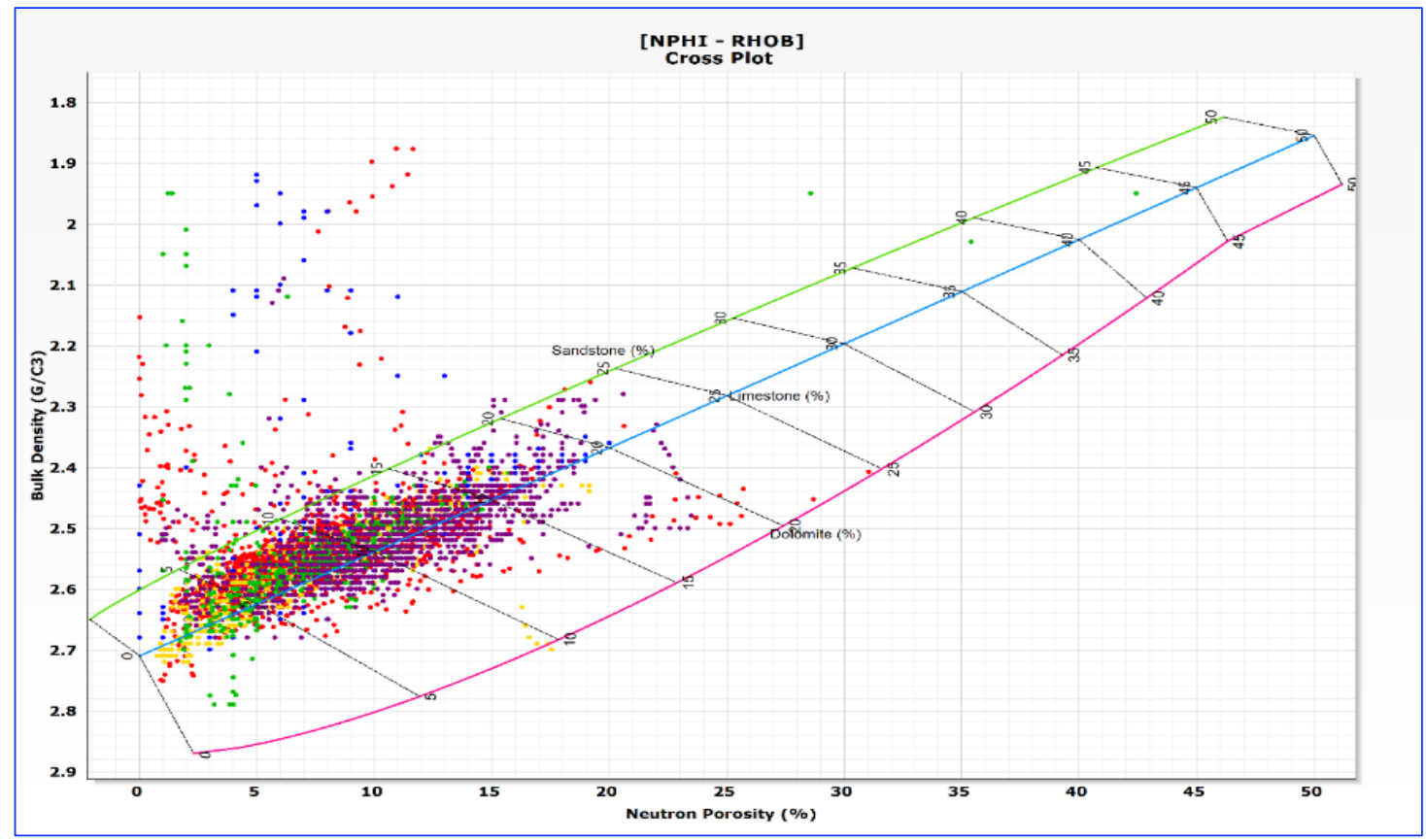

Fig.1. Neutron vs Density cross plot lithology identification

\section{Discussion}

A correct estimate of rock and fluid components and the use of corrected logs that discriminate between a combination of minerals and the components will ensure that the calculations are accurate and reliable. In case the rocks component known, a statistical model is very useful and gives excellent results compared to the core result. Techlog program is a very easy and reliable program for computer program interpretation (CPI); it has all the required equations for a statistical model. 


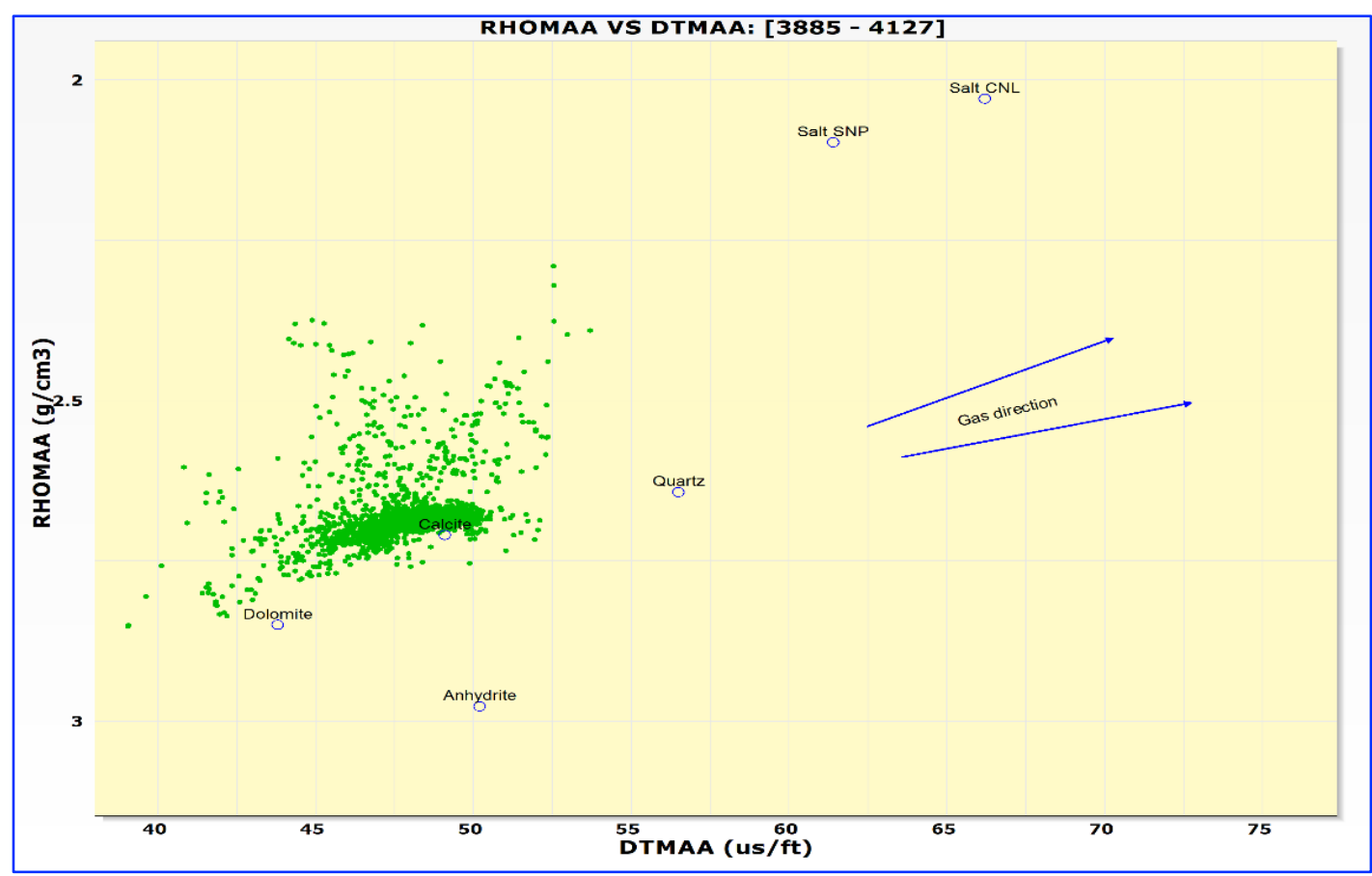

Fig.2. MID Plot Matrix Identification

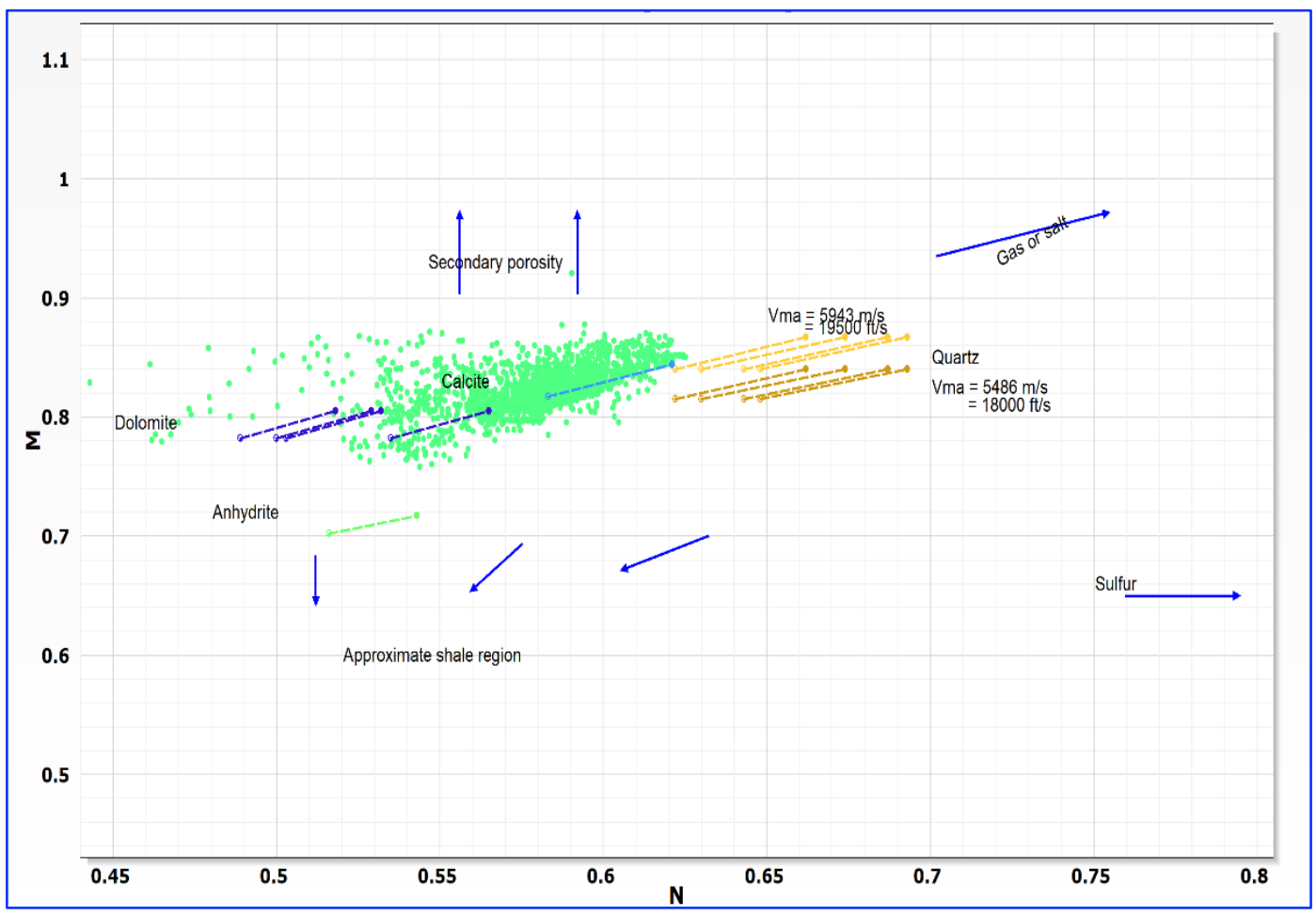

Fig.3. M vs N plot lithology identification 


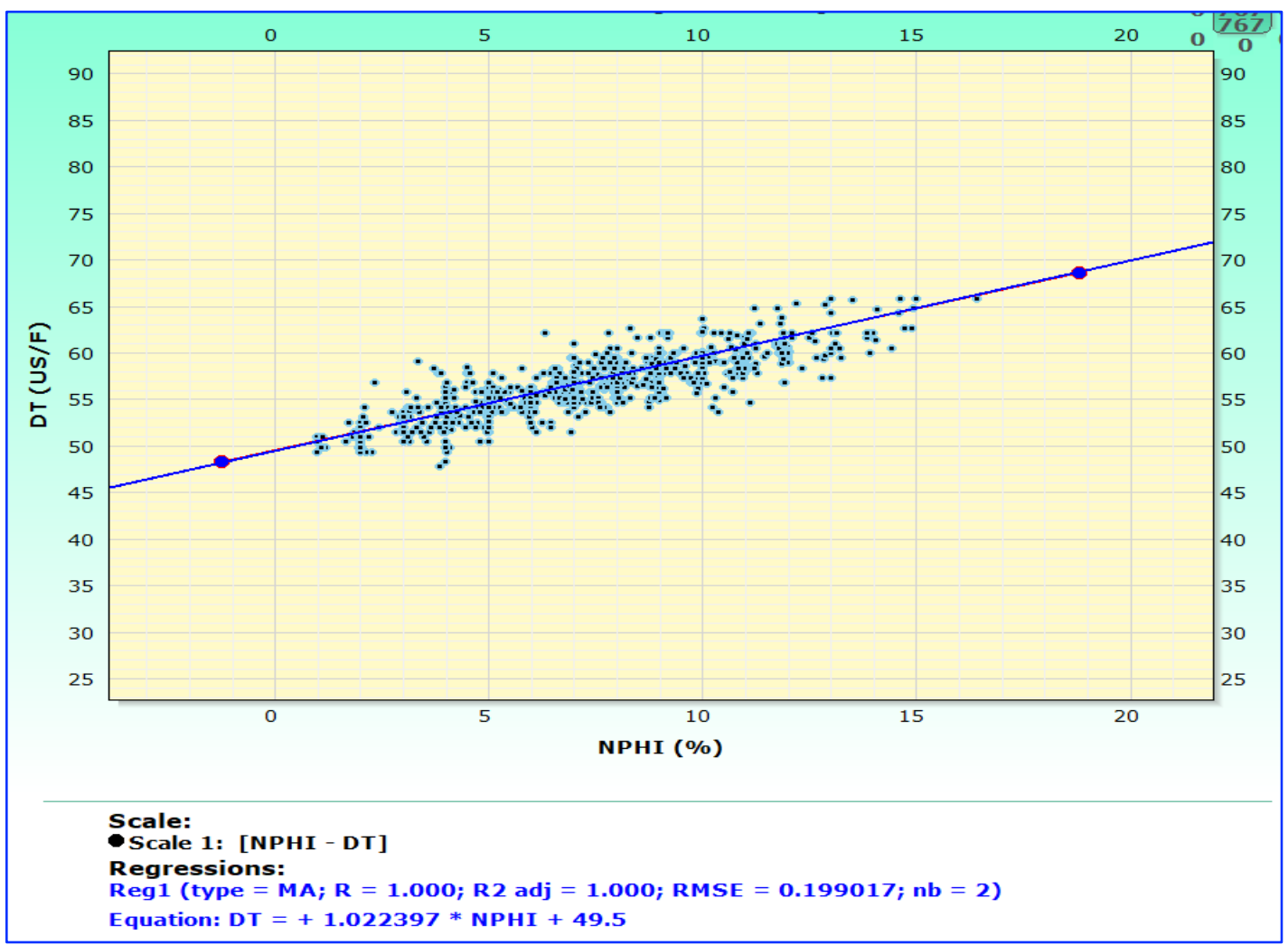

Fig.4. Sonic log vs Neutron log for $\Delta t_{\text {matrix }}$ identify

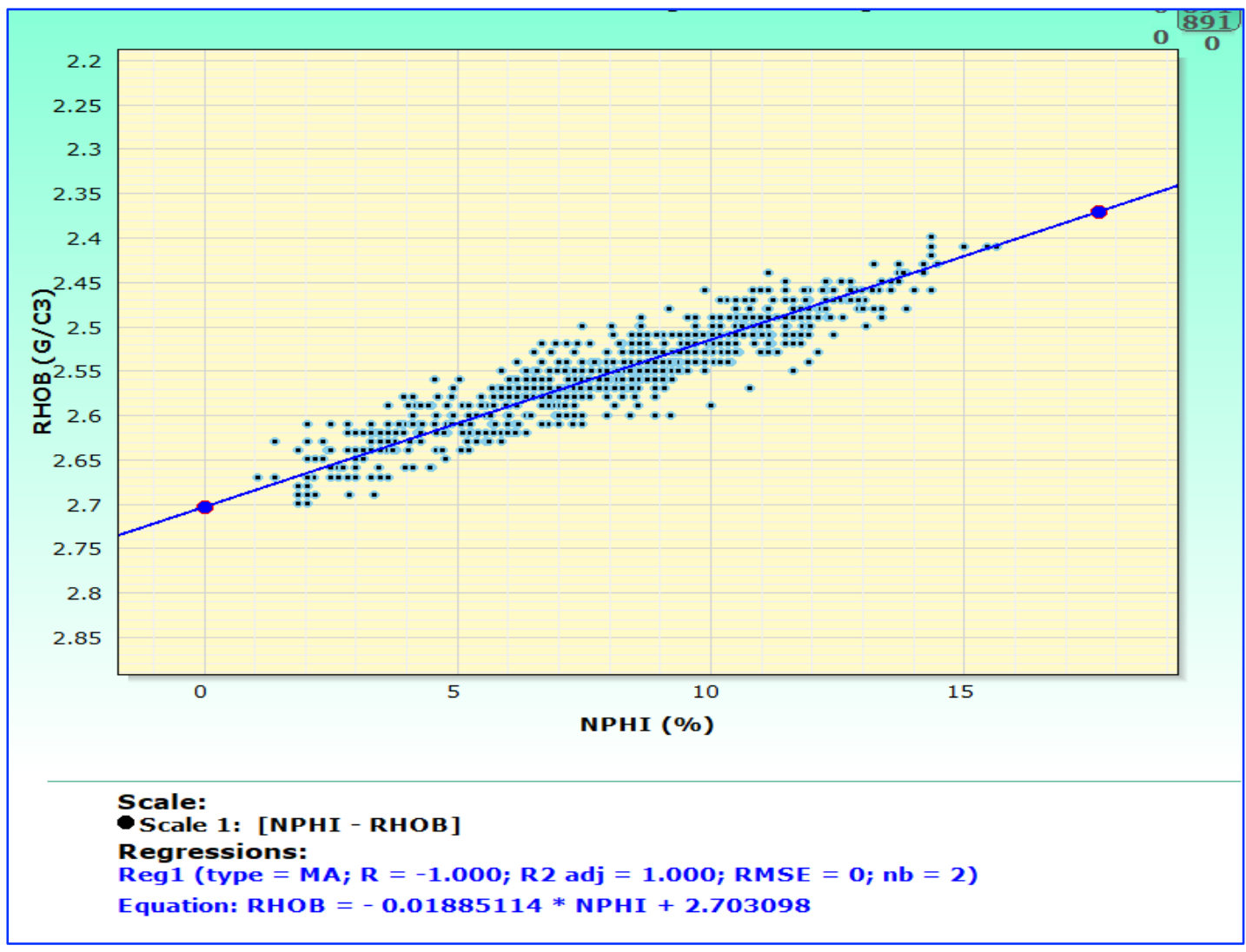

Fig. 5. Density log vs Neutron log for $\rho$ matrix identify 


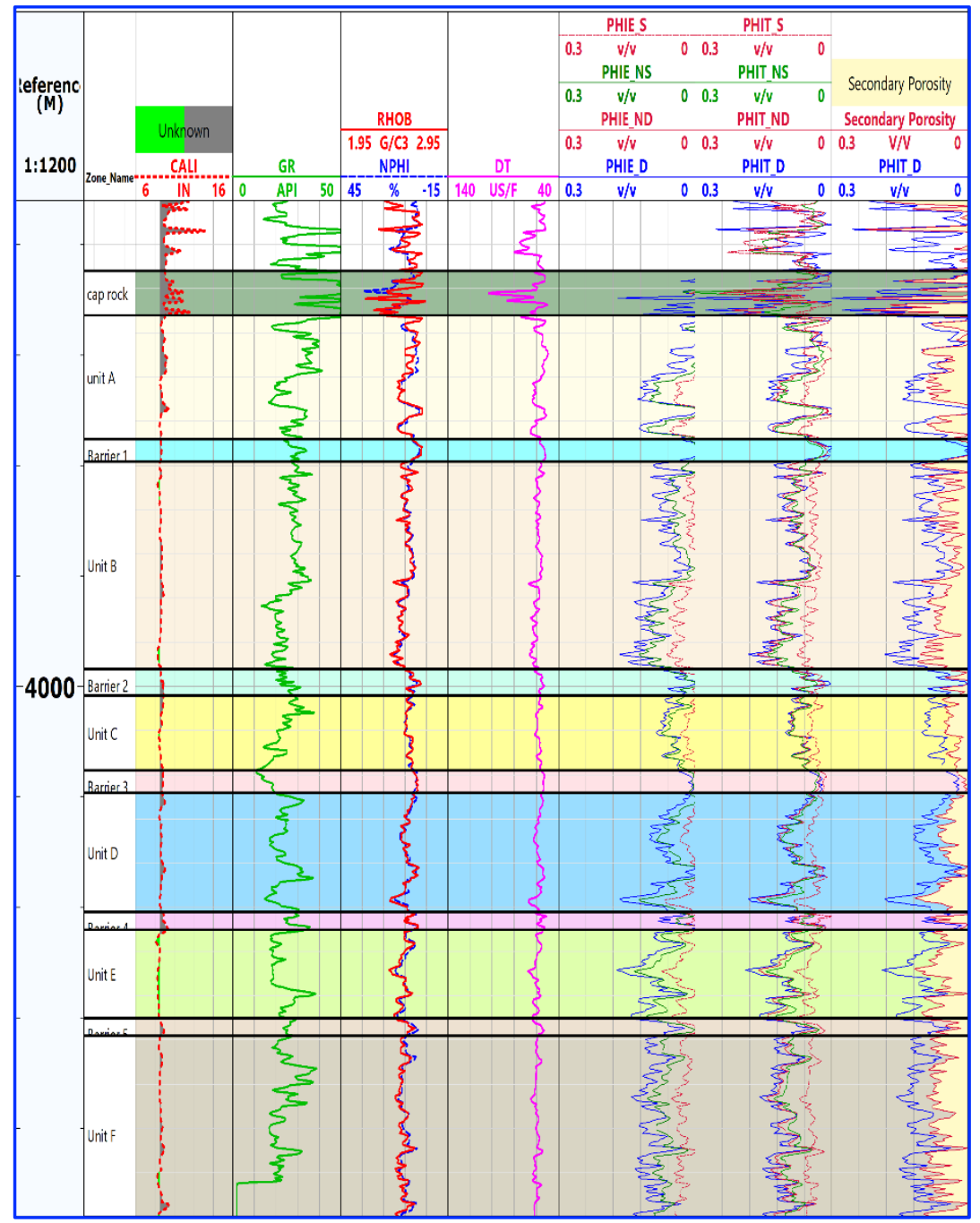

Fig.6. Porosity results

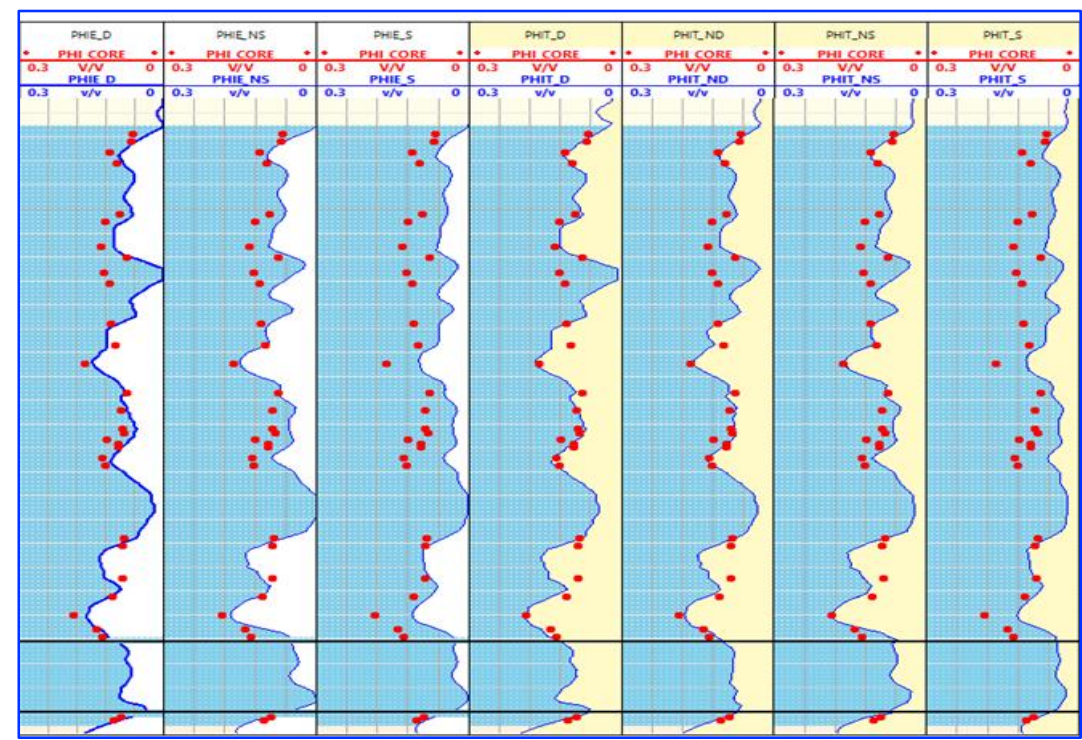

Fig.7. Core data with log porosity 


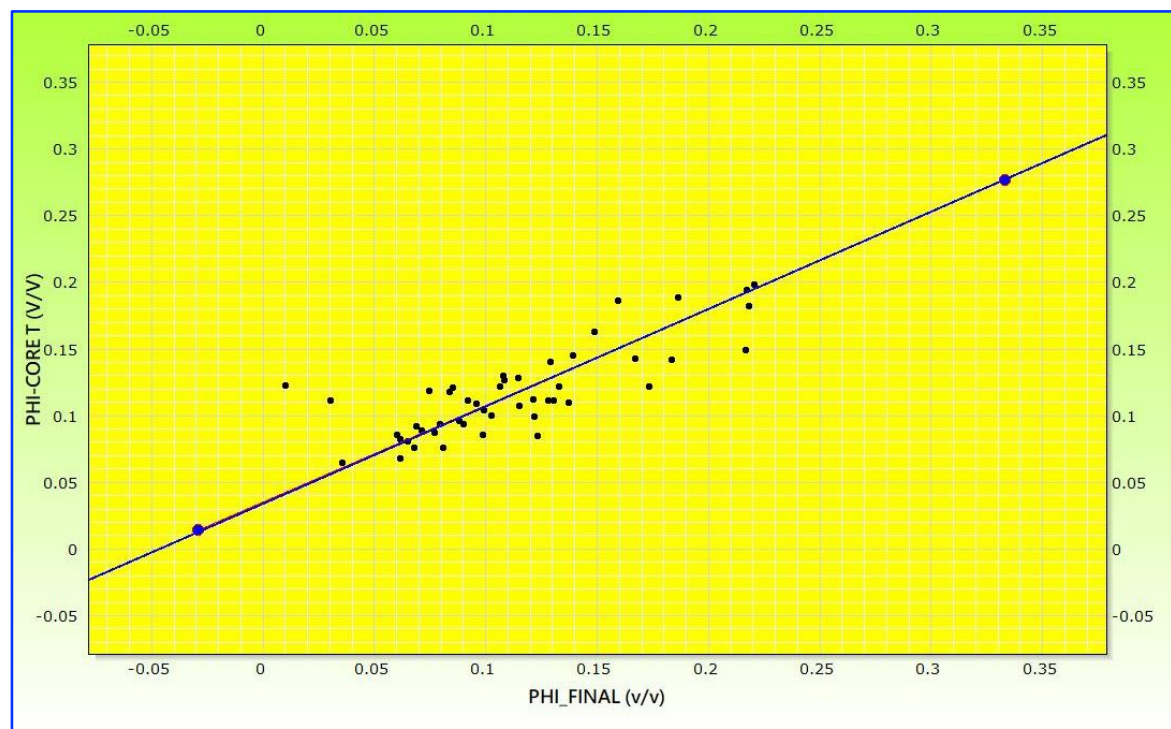

Scale:

Scale 1: [PHI_FINAL - PHI-CORET]

Reg1 (type = MA; $R=1.000 ; R 2$ adj $=1.000 ; R M S E=0.00143767 ; n b=2$ )

Equation: PHI-CORE T $=+0.73$ * PHI_FINAL +0.034

Fig.8. Core porosity vs log porosity

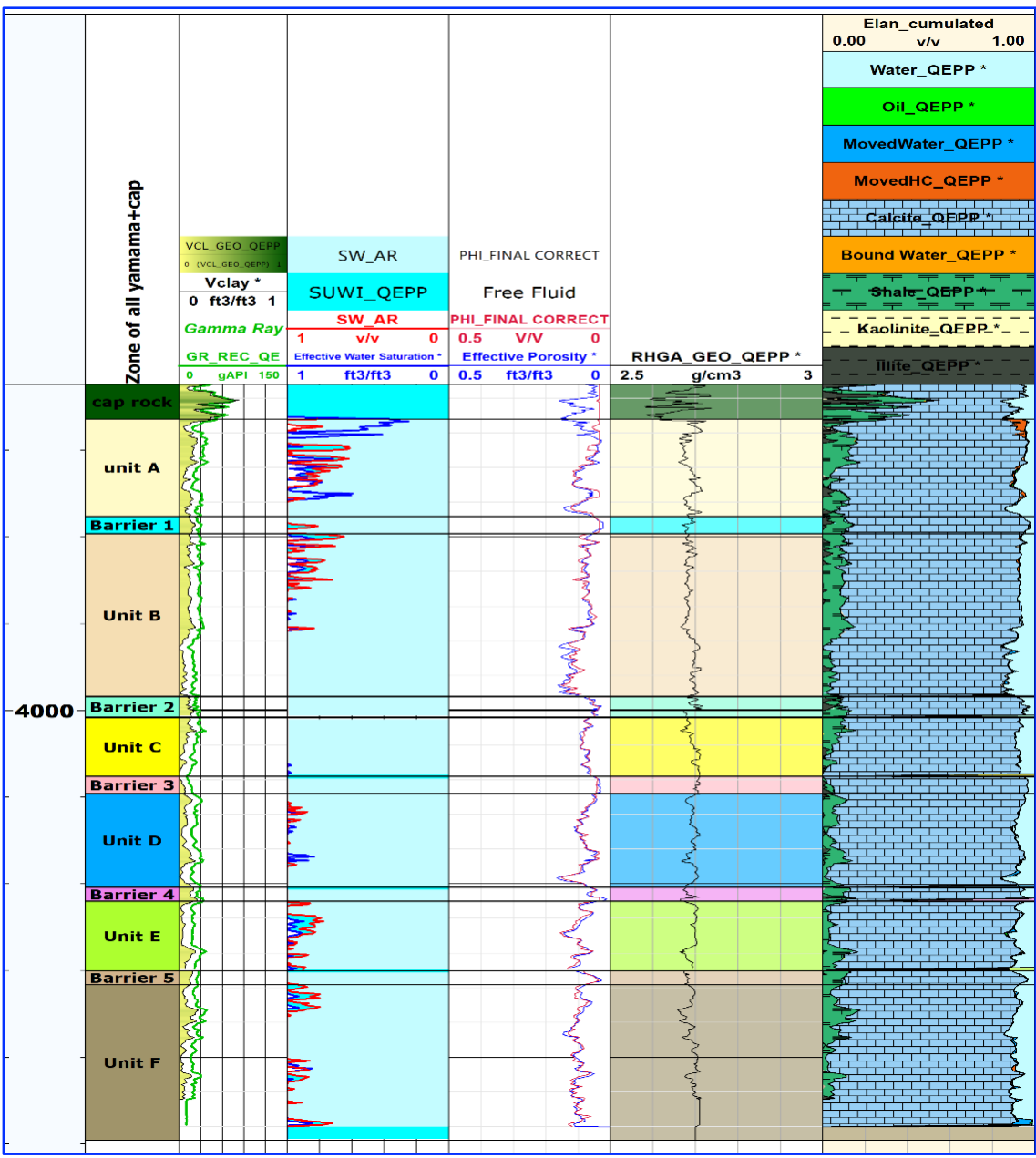

Fig.9. Factors of statistical model 


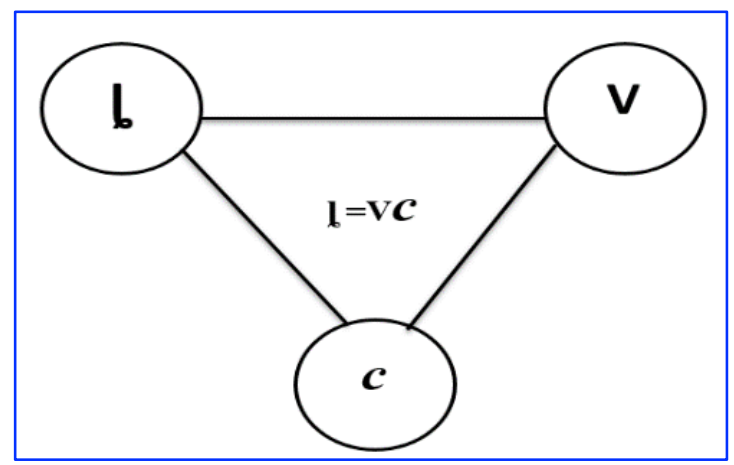

Fig.10. Statistical model (track no. 5 porosity)

\section{Conclusions}

In addition to conventional models, the employment of statistical models provides a new way of computation and a validation of the results obtained. Porosity calculated by a statistical model is more accurate due to logs to get the result and effect of bad hole condition and log low resolution be little.

\section{Acknowledgements}

I want to thank and appreciate all persons who help me in carrying out this work. The authors are very grateful to the Editor in Chief Prof. Dr. Salih M. Awadh, the Secretary of Journal Mr. Samir R. Hijab. and the Technical Editors for their great efforts and valuable comments.

\section{References}

Al-Baldawi, B. A., 2021. Evaluation of petrophysical properties using well logs of Yamama Formation in Abu Amood Oil Field, Southern Iraq. The Iraqi Geological Journal, 67-77.

Awadh, S.M., Al-Auweidy, M.R. and Al-Yaseri, A.A., 2019. Hydrochemistry as a tool for interpreting brine origin and chemical equilibrium in oilfields: Zubair reservoir southern Iraq case study. Applied Water Science, 9(3),1-12.

Awadh, S.M., Al-Mimar, H.S. and Al-Yaseri, A.A., 2018. Salinity mapping model and brine chemistry of Mishrif reservoir in Basrah oilfields, Southern Iraq. Arabian Journal of Geosciences, 11(18), 1-12.

Boschetti, T., Awadh, S.M., Al-Mimar, H.S., Iacumin, P., Toscani, L., Selmo, E. and Yaseen, Z.M., 2020. Chemical and isotope composition of the oilfield brines from Mishrif Formation (southern Iraq): Diagenesis and geothermometry. Marine and Petroleum Geology, 122, 104637.

Cannon, S., 2015. Petrophysics: a practical guide. John Wiley \& Sons.

Darling, T., 2005. Well logging and formation evaluation. Elsevier.

Ellis, D. V., \& Singer, J. M., 2007. Well logging for earth scientists (Vol. 692). Dordrecht: Springer. Hulea, I. N. (2013, March). Capillary pressure and permeability prediction in carbonate rocks-New methods for fractures detection and accurate matrix properties prediction. In SPE Middle East Oil and Gas Conference.

Idan, R. M., Salih, A. L., Al-Khazraji, O. N., \& Khudhair, M. H., 2020. Depositional Environments, Facies Distribution, and Porosity Analysis of Yamama Formation in Majnoon Oilfield. Sequence Stratigraphic Approach. Iraqi Geological Journal, 38-52.

Mahdi, T. A., 2020. Geological Model of Hartha Formation in Majnoon Oilfield, Southern Iraq. Iraqi Geological Journal, 48-57.

Nasser, M. E., Al-Jawed, S. N., \& Hassan, M. F., 2017. Geological modeling for Yamama Formation in Abu Amood oil field. Iraqi Journal of Science, 58(2C), 1051-1068.

Schlumberger, L. I., 1989. Principles and Applications. Schlumberger Education Services, Houston, Texas.

Schmidt, A. W., Land, A. G., Yunker, J. D., \& Kilgore, E. C., 1971. Applications of the CORIBAND technique to Complex lithologies. In SPWLA 12th Annual Logging Symposium. Society of Petrophysicists and WellLog Analysts. 